\title{
Abl Family Tyrosine Kinases Are Essential for Basement Membrane Integrity and Cortical Lamination in the Cerebellum
}

\author{
Zhaozhu Qiu, ${ }^{1}$ Yong Cang, ${ }^{2,4}$ and Stephen P. Goff ${ }^{1,2,3}$ \\ ${ }^{1}$ Department of Microbiology, ${ }^{2}$ Department of Biochemistry and Molecular Biophysics, and ${ }^{3}$ Howard Hughes Medical Institute, Columbia University \\ Medical Center, New York, New York 10032, and B Burnham Institute for Medical Research, La Jolla, California 92037
}

The Abl family nonreceptor tyrosine kinases, consisting of closely related Abl and Arg (Abl-related gene), play essential roles in mouse neurulation, but their functions in the subsequent development of CNS are poorly understood. Here, we show that conditional deletion of $A b l$ in precursors of neurons and glia on an Arg knock-out background leads to striking cerebellar malformations, including defects in anterior cerebellar morphogenesis, granule cell ectopia, and hypoplasia. Time course analyses reveal that the abnormal anterior cerebellar foliation results from local disruptions of the basement membrane (BM) located between radial glial endfeet and the meninges during embryonic cerebellar development. Granule cell ectopia and hypoplasia are also associated with the breaches in the BM and abnormal Bergmann glial networks during postnatal cerebellar development. In vitro culture experiments indicate that Abl/Argdeficient granule cells can interact with glial processes and proliferate normally in response to sonic hedgehog compared to cells isolated from control mice. Consistent with these findings, selective ablation of Abl family kinases in cerebellar granule cells alone does not cause any abnormality, suggesting that deletion of $A b l / A r g$ from glia is likely required for the mutant phenotype. Together, these results provide compelling evidence that $\mathrm{Abl}$ and Arg play key redundant roles in BM maintenance and cortical lamination in the cerebellum.

\section{Introduction}

Cortical structures in the mature mammalian CNS consist of defined cell layers that are formed by a series of well orchestrated cell specification and migration events. The cerebellum has long provided an excellent model system to study the lamination process (Hatten, 1999; Sillitoe and Joyner, 2007). In the cerebellar cortex, Purkinje cells arise from the ventricular zone and migrate radially toward the cerebellar surface. Granule cell precursors (GCPs) are generated by the rhombic lip and move tangentially across the surface of the cerebellar primordium to form a secondary germinal zone, the external granular layer (EGL). After birth, granule cells that are produced in the EGL migrate radially inward through the Purkinje cell layer (PCL) to form the internal granular layer (IGL), and this occurs simultaneously with the formation and growth of the folia.

The pial basement membrane (BM) is a network of extracellular matrix (ECM) proteins secreted by meningeal fibroblasts (Sievers et al., 1994), and its integrity is critical for corticogenesis. Mutant mice with deletions in some members of BM components (perlecan and laminin $\alpha 5$ and $\gamma 1$ ), their cellular receptors

Received June 3, 2010; revised Aug. 12, 2010; accepted Aug. 26, 2010.

This work was supported by National Cancer Institute Grant P01 CA023767 (S.P.G.). We thank Tony Koleske for $\mathrm{Arg}^{-1-}$ mice, Alex Joyner for Math1-Cre mice, Hae Young Lee for recombinant Shh, Carol Mason, Alex Joyner, Hynek Wichterle, and Mary Hatten for advice, Shahin Aeinehband, Hae Young Lee, Yu Shi, Alex Rebsam, and Turgay Akay for technical assistance, and members of the laboratory for helpful discussions.

Correspondence should be addressed to Stephen P. Goff, 701 West 168th Street, Hammer Health Sciences Center 1310, Columbia University, New York, NY 10032. E-mail: spg1@columbia.edu.

DOI:10.1523/JNEUROSCI.2861-10.2010

Copyright $\odot 2010$ the authors $\quad 0270-6474 / 10 / 3014430-10 \$ 15.00 / 0$
( $\alpha$-dystroglycan, integrins $\beta_{1}$ and $\alpha_{6}$ ), or downstream associates of integrins such as FAK (focal adhesion kinase) and ILK (integrin-linked kinase) show BM disruptions and cortical and cerebellar abnormalities (Georges-Labouesse et al., 1998; Miner et al., 1998; Costell et al., 1999; Graus-Porta et al., 2001; Halfter et al., 2002; Moore et al., 2002; Beggs et al., 2003; Niewmierzycka et al., 2005; Belvindrah et al., 2006, 2007; Mills et al., 2006; Satz et al., 2008). These defects resemble the cobblestone lissencephaly found in a subclass of congenital muscular dystrophy, and most of them are caused by aberrant glycosylation of $\alpha$-dystroglycan, a laminin receptor (Olson and Walsh, 2002; Barresi and Campbell, 2006).

The Abl family nonreceptor tyrosine kinases contain Src homology 3 (SH3), SH2, tyrosine kinase domains, and unique carboxyl-terminal halves with many functional domains (Pendergast, 2002). A prominent function of Abl kinases is to transduce signals from cell surface receptors into cytoskeletal reorganizations that have dramatic effects on cell morphology and motility (Woodring et al., 2003; Bradley and Koleske, 2009). Mouse embryos deficient in both Abl and Arg suffer from a defect in neurulation and die at embryonic day (E) 11, although disruption of either gene alone causes no obvious brain malformation (Schwartzberg et al., 1991; Tybulewicz et al., 1991; Koleske et al., 1998). Here, we show that CNS-specific deletion of $A b l$ in the $\mathrm{Arg}^{-1-}$ mice results in severe cerebellar dysplasia and hypoplasia associated with the loss of the BM, which resemble cerebellar abnormalities seen in cobblestone lissencephaly. The absence of any morphological defect following granule cell-specific deletion of $\mathrm{Abl}$ on the same background indicates that the cerebellar phe- 
A

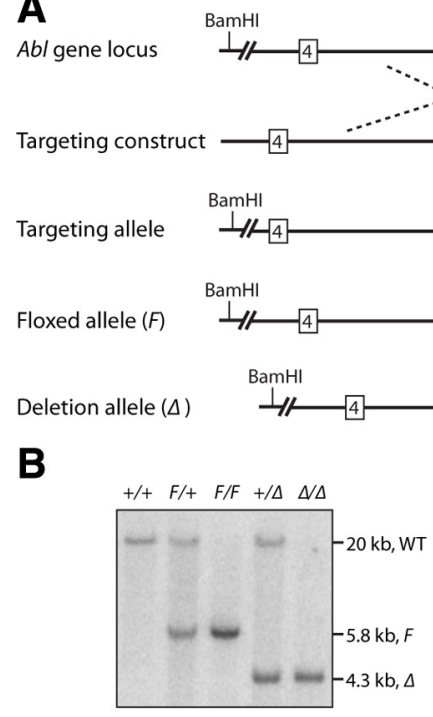

D

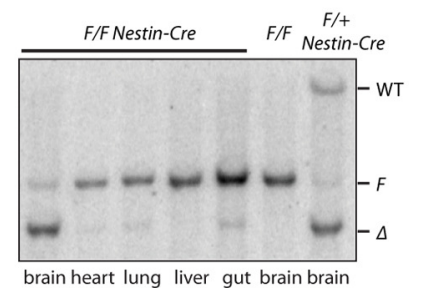

Figure 1. Generation of CNS-specific $A b /$ knock-out mice. $A$, Diagram of the $A b /$ genomic locus, the targeting construct, and the targeted alleles. The exons (open rectangles), loxP sites (red triangles), neomycin resistance cassette (neo, blue rectangle), Southern blot probe, and positions of $P C R$ primers (small arrows) for genotyping are indicated. $\boldsymbol{B}, \boldsymbol{C}$, Southern blot $(\boldsymbol{B})$ and $P C R(\boldsymbol{C})$ analyses of tail DNA from mice containing various combinations of the targeted alleles. For Southern blots, DNA was digested with BamHI and hybridized to the probe as indicated in $\boldsymbol{A}$. $\boldsymbol{D}, \boldsymbol{E}$, Southern blot $(\boldsymbol{D})$ and Western blot $(\boldsymbol{E})$ analyses of multiple tissues dissected from newborn mice with indicated genotypes showing brain-specific $A b /$ deletion induced by Nestin-Cre. WT, wild type.

anti-laminin (1:200; Sigma), rabbit anti-BLBP (1: 400; Abcam), mouse anti-NeuN (1:500; Millipore), mouse anti-GFAP (1:800; Millipore), rat anti-BrdU (1:200; Abcam), rat anti-L1 (1:200; Millipore), mouse anti-TAG1 (1:4; Developmental Studies Hybridoma Bank, University of Iowa, Iowa City, IA), mouse anti-Crk (1:4000; BD Biosciences), rabbit anti-phospho-CrkII (Tyr221) (1:1000; Cell Signaling Technology), and mouse anti-p130Cas (1:1000; BD Biosciences).

Histological analysis and immunohistochemistry. Embryos and postnatal mice were fixed or perfused with neutral buffered $10 \%$ formalin. Brains were either cryoprotected by $20 \%$ sucrose in PBS and embedded in OCT for frozen sections $(15 \mu \mathrm{m})$ or embedded in paraffin for paraffin sections $(7 \mu \mathrm{m})$. Hematoxylin and eosin (H\&E) and lacZ stains were performed following standard procedures. Immunohistochemistry was performed as described previously (Qiu et al., 2010). Briefly, paraffin sections were subjected to heatinduced antigen retrieval in $10 \mathrm{~mm}$ sodium citrate buffer. After blocking in 10\% normal donkey serum, frozen and paraffin sections were incubated with primary antibodies and then with Alexa Fluor-conjugated secondary antibodies (Invitrogen). Slides were finally mounted with Vectashield mounting medium with 4',6-diamidino-2-phenylindole (Vector Laboratories).

$B r d U$ labeling. Pups were intraperitoneally injected with bromodeoxyuridine (BrdU; 100 $\mathrm{mg} / \mathrm{kg}$ body weight; Sigma) and their brains were dissected after either $1 \mathrm{~h}$ or $4 \mathrm{~d}$. For staining, sections were incubated with $2 \mathrm{~N} \mathrm{HCl}$ for $30 \mathrm{~min}$ at $37^{\circ} \mathrm{C}$ before the application of antibodies.

Immunoprecipitation, active Racl pull-

notype is likely caused by the failure of radial glia and Bergmann glia to maintain the BM rather than a cell-autonomous defect in granule cell migration and proliferation. These findings establish Abl family kinases as essential signaling components in the regulation of BM integrity during cerebellum development.

\section{Materials and Methods}

Generation of $A b l^{F}$ mice. The $3^{\prime}$ arm of the targeting vector for generation of the floxed $\mathrm{Abl}$ allele contained $2.1 \mathrm{~kb}$ genomic sequences covering exon 7 (see Fig. $1 A$ ). The $5^{\prime}$ arm of the vector harbored exons $4-6$ of the $A b l$ gene, with one loxP site inserted at the end of intron 4 . The neomycin resistance cassette (neo) flanked by two loxP sites was inserted into the middle of intron 6. Following homologous recombination in E14 embryonic stem (ES) cells, an expression vector of Cre recombinase ( $\mathrm{Gu}$ et al., 1993) was transiently transfected to delete the neo cassette. Clones that retained two loxP sites flanking exons 5 and 6 were identified by Southern analysis. Two independent heterozygous ES cell clones were used to generate chimeric mice by blastocyst injection. $A b l^{F}$ mice were mated with various mouse lines, including $\mathrm{Arg}^{-1-}$ (Koleske et al., 1998), a kind gift from Tony Koleske (Yale University, New Haven, CT), EIIa-Cre (JAX \#3724), Nestin-Cre (JAX\#3771), Emx1-Cre (JAX\#5628), and Math1-Cre (Matei et al., 2005), a kind gift from Alex Joyner (Sloan-Kettering Institute, New York, NY). ROSA26lacZ reporter line (Soriano, 1999) was obtained from The Jackson Laboratory (JAX \#3474). All mutant animals were bred on a mixed $129 \times \mathrm{C} 57 \mathrm{BL} / 6 \mathrm{~J}$ background. All animal procedures were approved by the Columbia University Institutional Animal Care and Use Committee (New York, NY).

Antibodies. Mouse anti-Abl (1:1000; Calbiochem), mouse anti- $\alpha$-tubulin (1:5000; Sigma), rabbit anti-Pax6 (1:500, Millipore), mouse anti-calbindin (1:5000; Swant), rabbit anti-ROR $\alpha$ (1:50; Santa Cruz Biotechnology), rabbit down, and Western blot. Tissues from newborn mice were homogenized in lysis buffer (20 mm Tris, pH 7.5, $150 \mathrm{~mm} \mathrm{NaCl,} 2$ mM EDTA, $1 \%$ Nonidet P-40) supplemented with protease inhibitors (Roche). After centrifuging at $15,000 \times g$ for $15 \mathrm{~min}$, supernatant was recovered and protein concentration was determined by the Bio-Rad protein assay. Equal amounts were resolved on $8 \%$ SDS-PAGE gels and analyzed by Western blot using a standard protocol. For immunoprecipitaion, $2 \mathrm{mg}$ of brain extracts were incubated with anti-Crk antibody-conjugated protein G Dynabeads (Invitrogen) and washed three times with PBS before resolution on 10\% SDS-PAGE gels. Active Rac1 GTPase levels were determined using a GST-Pak1-PBD pull-down assay (Thermo Scientific) according to the manufacturer's instruction.

Cerebellar cell culture. Granule cells and glia were purified from postnatal day (P) 4-5 cerebella according to a previously described procedure (Lee et al., 2009). Briefly, after the removal of meninges, a single-cell suspension from cerebella was obtained using the Papain Dissociation System Kit (Worthington). For granule cell proliferation assay, the cell suspension was applied to a Percoll gradient and separated by centrifugation. Enriched granule cells at the interface between the 35 and $60 \%$ Percoll gradients were cultured on $100 \mu \mathrm{g} / \mathrm{ml}$ poly-D-lysine (Sigma)precoated coverslips for $2 \mathrm{~d}$ in serum-free medium with or without 3 $\mu \mathrm{g} / \mathrm{ml}$ sonic hedgehog (Shh), a kind gift from Hae Young Lee, Columbia University. Four hours before fixation, cultures were treated with $10 \mu \mathrm{M}$ BrdU. For glia-guided granule cell migration (Hatten et al., 1986), the single-cell suspension was passed through a $40 \mu \mathrm{m}$ cell strainer and preplated on an uncoated dish to remove residual contaminating fibroblasts. The resulting granule cell and glia mixtures were cultured on $100 \mu \mathrm{g} / \mathrm{ml}$ poly-D-lysine $/ 10 \mu \mathrm{g} / \mathrm{ml} \mathrm{laminin} \mathrm{(Sigma)-precoated} \mathrm{coverslips} \mathrm{for} 24 \mathrm{~h}$. 
Balance beam assay. The balance beam assay of motor coordination was performed as described previously (Stanley et al., 2005). One to two-month-old mice of both genders were first trained to walk on a wide $(20 \mathrm{~mm}$ width $\times 60$ $\mathrm{cm}$ length) and then a narrow $(8 \mathrm{~mm}$ width $\times$ $60 \mathrm{~cm}$ length) elevated balance beam to reach a goal platform. At the end of training trials, the mice would start to walk within a few seconds of being placed on the beam. Each test trial on the narrow beam consisted of five walks per mouse. Time to cross the beam and number of foot slips were recorded for each trial.

Statistical analysis. Data are expressed as mean \pm SEM. and were evaluated by unpaired Student's 2-tailed $t$ test. Values were considered statistically significant at $p<0.05$.

\section{Results}

Generation of CNS-specific $A \boldsymbol{b l}$

knock-out mice on the $\mathrm{Arg}^{-/-}$

\section{background}

To investigate the role of $\mathrm{Abl}$ in CNS development, a floxed allele of $A b l\left(A b l^{F}\right)$ was generated using Cre/loxP technology. LoxP sites upstream of exon 5 and downstream from exon 6 were introduced into ES cells by homologous recombination (Fig. 1A). Upon Cre-mediated recombination, excision of the fifth exon and sixth exon would delete part of the tyrosine kinase domain and fully inactivate the gene as determined by Western blot (supplemental Fig. S1, available at www. jneurosci.org as supplemental material, Fig. $1 E)$, creating an $A b l$-null allele $\left(A b l^{\Delta}\right)$. Splicing of the primary transcript to join the flanking exons, if it occurred, would produce a frameshift mutation. $A b l^{F / F}$ mice appeared healthy and indistinguishable from their wildtype littermates. $A b l^{F}$ mice were first bred to males expressing an EIIa-Cre transgene (Agah et al., 1997), which deletes loxP-targeted DNAs in the germline, generating the $A b l^{\Delta}$ allele. Mice with combinations of different $A b l$ alleles (wild-type, $A b l^{F}$ and $A b l^{\Delta}$ ) were genotyped by Southern blot (Fig. $1 B$ ) and PCR analyses (Fig. 1C) of tail DNA. Intercrosses to generate homozygotes of the $A b l^{\Delta}$ allele resulted in partial neonatal lethality with various developmental defects, such as runting, splenic, and thymic atrophy (supplemental Fig. S1, available at www.jneurosci.org as supplemental material), consistent with the previous descriptions of Abl-null mice (Schwartzberg et al., 1991; Tybulewicz et al., 1991).

CNS-specific inactivation of Abl was accomplished by crossing $\mathrm{Abl}^{F}$ mice to a transgenic line expressing Cre under the control of the rat nestin promoter and enhancer (Nestin-Cre) (Tronche et al., 1999). Nestin-Cre was shown to induce potent and widespread recombination in precursors of neurons and glia starting around E10 (Graus-Porta et al., 2001). Genomic DNA from multiple tissues dissected from $A b l^{F / F} ;$ Nestin-Cre or control newborns were analyzed by Southern blot analysis, confirming efficient recombination within the floxed $A b l$ allele specifically in the brain (Fig. $1 D$ ). Furthermore, Western blot analysis of extracts
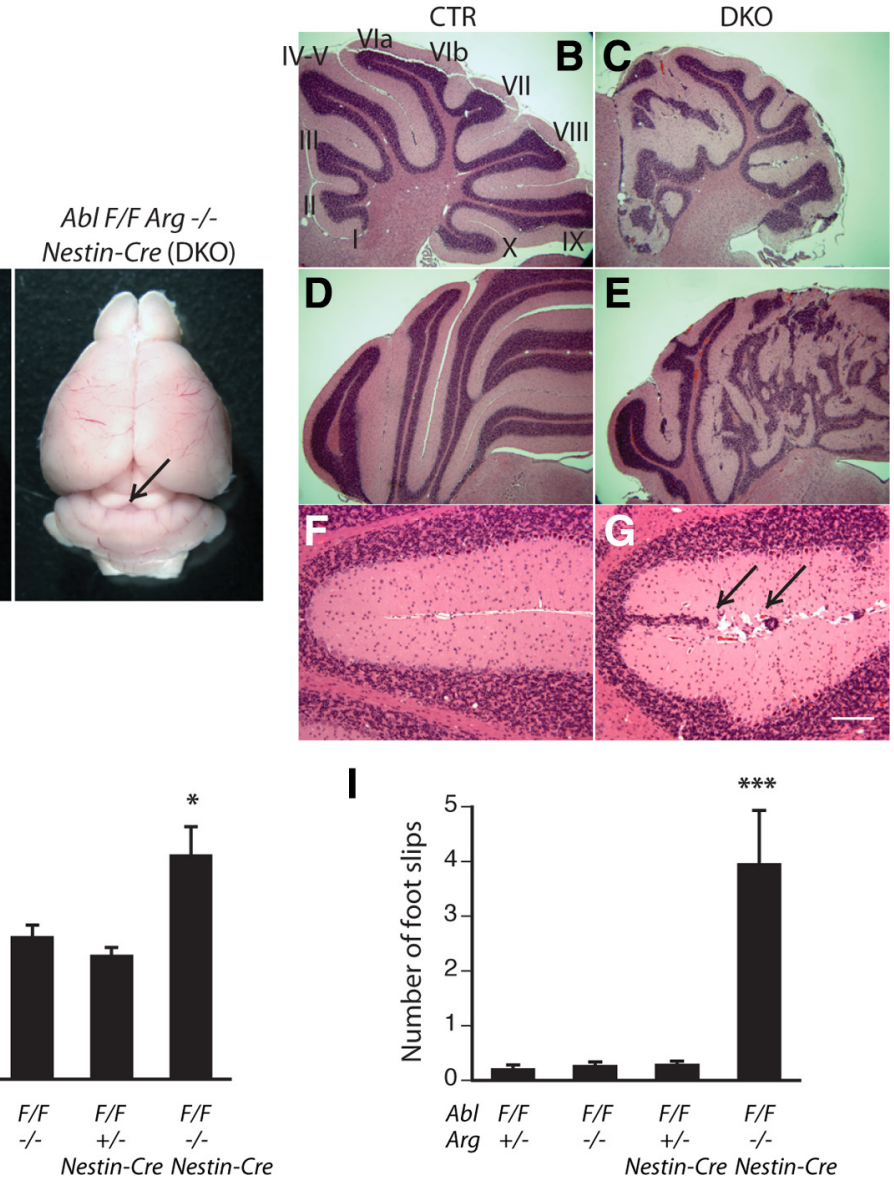

Figure 2. Abl/Arg deficiency in the brain results in cerebellar malformations and motor coordination deficits. $\boldsymbol{A}$, Pictures of whole brains dissected from adult $A b / / A r g$ CNS-DKO mouse and its control littermate (CTR) showing the gross abnormalities in the

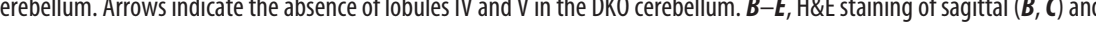
IX in the DKO cerebellum. $\boldsymbol{H}, \boldsymbol{I}, \mathrm{AbI} / \mathrm{Arg}$ CNS-DKO mice exhibited compromised ability in the balance beam test. The time for the mice to cross the beam and number of foot slips were measured. $n=5-8$ mice for each genotype. Mean \pm SEM, ${ }^{*} p<0.05$, ${ }^{* * *} p<$ 0.005 , Student's $t$ test. Scale bar: (in $\boldsymbol{G}) \boldsymbol{B}-\boldsymbol{E}, 500 \mu \mathrm{m} ; \boldsymbol{F}, \boldsymbol{G}, 125 \mu \mathrm{m}$.

from $A b l^{F / F}$;Nestin-Cre newborns showed nearly complete loss of Abl protein in the brain, but not in the adjacent meninges (Fig. 1E). $A b l^{F / F}$;Nestin-Cre mice were grossly normal and histological analysis of the brain revealed no obvious morphological defects. This was not a surprise, since no brain malformation was detected in Abl knock-out mice (Schwartzberg et al., 1991; Tybulewicz et al., 1991). We then crossed $\mathrm{Abl}^{\mathrm{F} / F} ;$ Nestin-Cre mice onto an $\mathrm{Arg}^{-1-}$ background (Koleske et al., 1998) and generated $\mathrm{Abl}^{\mathrm{F} / \mathrm{F}} ; \mathrm{Arg}^{-1-}$; Nestin-Cre mice, which we refer as Abl/Arg CNS-specific double conditional knock-out (CNS-DKO) mice hereafter.

\section{Abl/Arg deficiency in the brain results in severe cerebellar lamination defects and motor coordination deficits}

Abl/Arg CNS-DKO mice were viable and recovered at a frequency (20.5\%) slightly less than the expected Mendelian ratio (supplemental Table 1, available at www.jneurosci.org as supplemental material). Whole-mount analysis of the CNS-DKO young adult brain revealed profound irregularities in the cerebellum, while the rest of brain appeared normal (Fig. $2 A$ ). The phenotype was observed in all DKO mice examined, but not in their control littermates. The brains from those mice that still retained at least one functional copy of either $A b l$ or $A r g$ gene (e. g. $A b l^{F /+} ; \mathrm{Arg}^{-1-}$; Nestin-Cre) were normal upon histological examination, indi- 


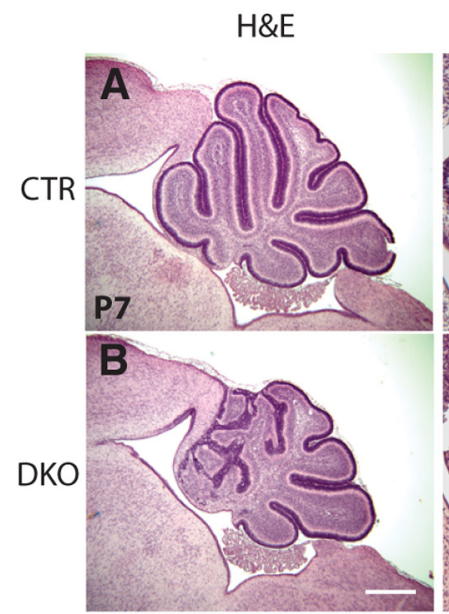

$H \& E$

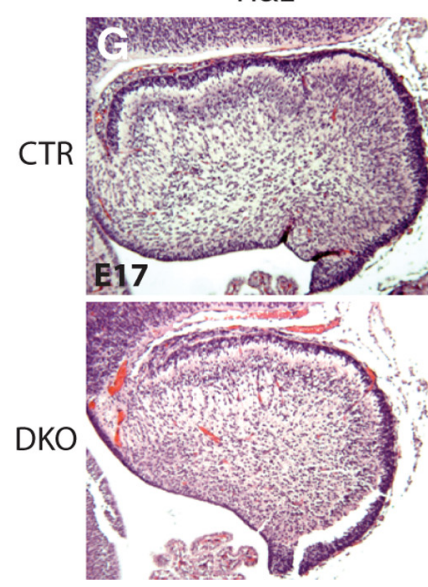

Pax6
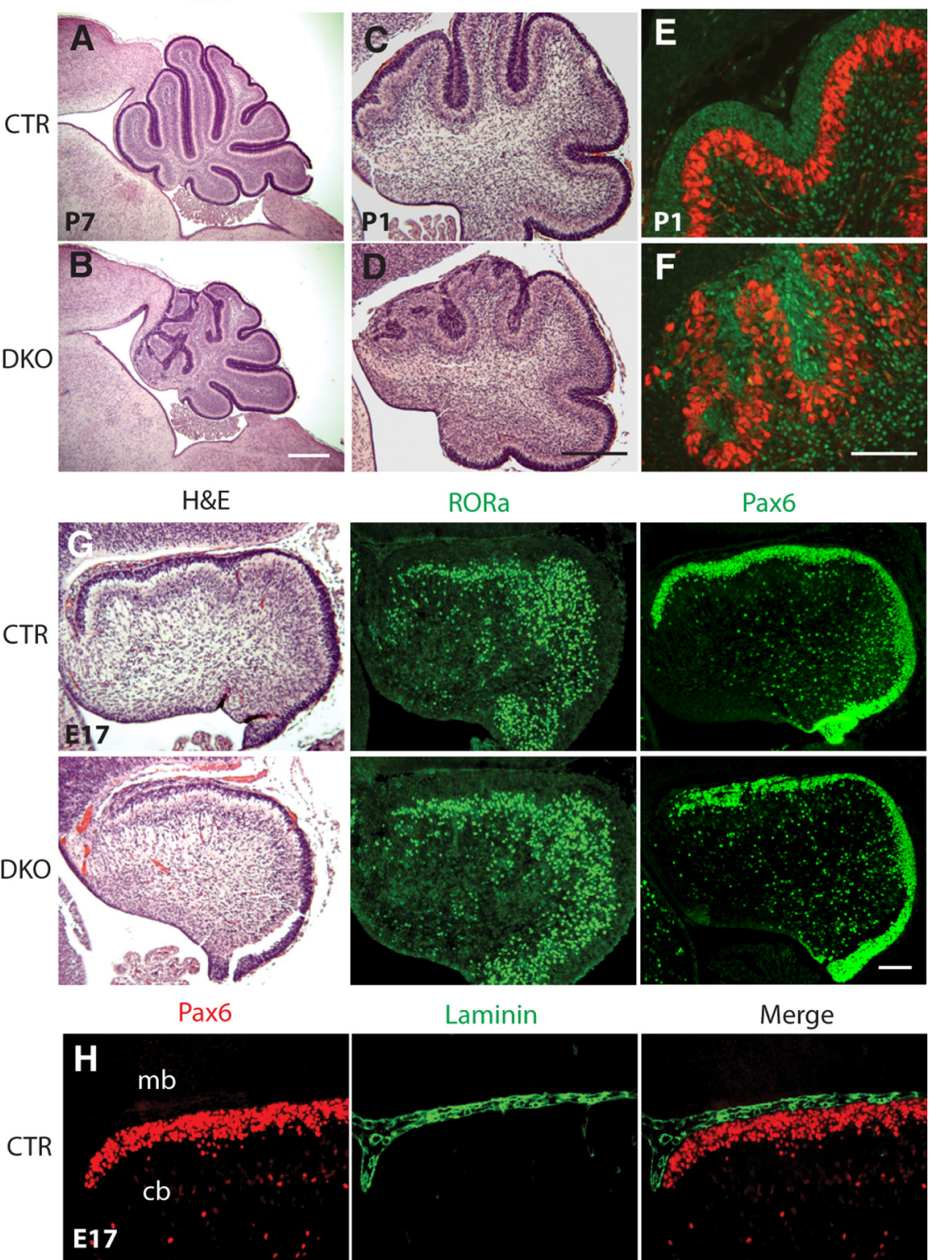

Laminin
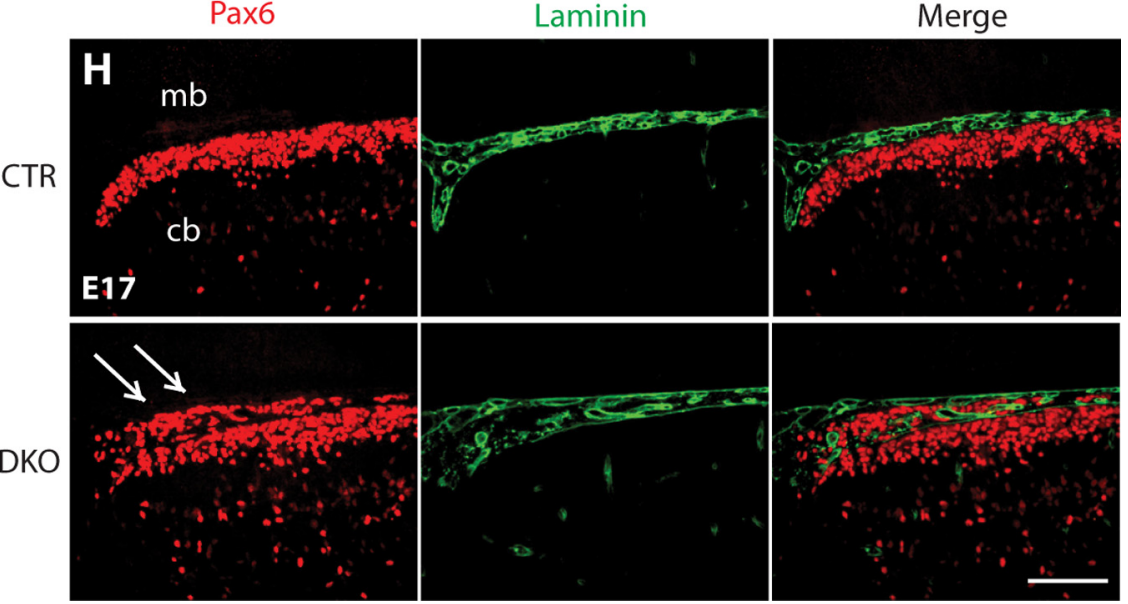

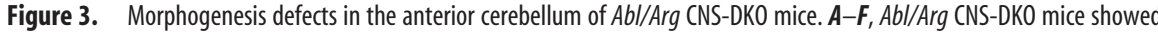
foliation defects in the anterior cerebellum at early postnatal stages. $\boldsymbol{A}-\boldsymbol{D}$, H\&E staining of P7 and P1 control (CTR) and DKO cerebellar sections. $\boldsymbol{E}, \boldsymbol{F}, \mathrm{Pax} 6$ and calbindin costaining of $\mathrm{P} 1$ anterior cerebellar sections. $\boldsymbol{G}, \boldsymbol{H}$, Granule cell precursors abnormally migrated into the subarachnoid space ( $\boldsymbol{H}$, arrows) between the midbrain (mb) and cerebellum (cb) in the DKO embryos. $\boldsymbol{G}, \mathrm{H \& E}$, ROR $\alpha$, and Pax6 staining of E17 CTR and DKO cerebellar sections. $\boldsymbol{H}$, Pax6 and laminin costaining of E17 CTR and DKO anterior cerebellar sections. Scale bars: (in $\boldsymbol{A}, \boldsymbol{D}) \boldsymbol{A}-\boldsymbol{D}, 500 \mu \mathrm{m}$; (in $\boldsymbol{F}, \boldsymbol{G}, \boldsymbol{H}) \boldsymbol{E}-\boldsymbol{H}, 100 \mu \mathrm{m}$.

cating that the functions of the two genes are largely redundant. The DKO cerebellum was smaller in size compared with control. The anterior-posterior extent of the mutant cerebellum, with the disappearance of lobules IV and V in the anterior vermis (Fig. $2 A$, arrows), was markedly reduced. Furthermore, both the cerebellar vermis and the two lateral hemispheres lacked clear fissures on the surface.
Histological analysis of the DKO brain revealed proper lamination of the cerebral cortex and hippocampus (supplemental Fig. S2, available at www.jneurosci.org as supplemental material). However, sagittal and coronal sections of the DKO cerebellum not only confirmed that its length along the anterior-posterior axis was dramatically reduced, but also revealed several other striking abnormalities (Fig. $2 B-G)$. First, the basic laminar structure of the anterior cerebellum, encompassing lobules I-V, was completely lost in the DKO mice. As a result, patches of granule cells were randomly scattered throughout the white matter. Second, although the basic foliation pattern of the hemispheres and the posterior cerebellum seemed to be preserved (supplemental Fig. S3, available at www.jneurosci.org as supplemental material), adjacent lobules, such as lobules VIII and IX, were fused and the depth of the fissures was also significantly decreased (Fig. 2F, G). Moreover, while a rudimentary IGL formed, many granule cells failed to migrate and formed ectopias at the cerebellar surface and along the fusion lines of adjacent lobules (Fig. 2F, G, arrows). Together, the histological analysis demonstrates that the development of cerebellar cortex is specifically compromised in the absence of Abl and Arg, leading to anterior cerebellar morphogenesis defects and cortical lamination abnormalities.

Considering the profound morphological defects in the cerebella of $\mathrm{Abl/Arg}$ CNS-DKO mice, we examined motor coordination function in these mutants. The DKO mice did not display obvious ataxia in an open field test. However, when placed on an elevated balance beam, differences between the DKO mice and their control littermates were evident (supplemental movies S1, S2, available at www. jneurosci.org as supplemental material): DKO mice took approximately twice as long to cross the beam (Fig. $2 \mathrm{H}$ ) and also demonstrated a dramatic increase in the number of foot slips (Fig. 2I). Thus, the DKO mice exhibit substantial motor coordination deficits that do not affect normal locomotor function but becomes apparent upon challenge with more complicated tasks. Like the cerebellar malformation, poor motor coordination was also observed only in the DKO mice, suggesting that the impairment of motor function is probably caused by cerebellar defects.

Disruption of the BM during embryonic development leads to morphogenesis defects in the anterior cerebellum

To determine the developmental stage at which the malformation of the anterior cerebellum arises, we examined Abl/Arg CNS- 
DKO mice at younger ages (Figs. 3, 4). Sagittal sections of P7 and P1 cerebella showed obvious defects in the organization of anterior lobules $\mathrm{I}-\mathrm{V}$ in the DKO mice (Fig. $3 A-D$ ). Immunostaining of $\mathrm{P} 1$ sections with markers for granule cells (Pax6) and Purkinje cells (calbindin) revealed that both cell types were mislocalized: many GCPs were ectopically embedded within the cortex and Purkinje cells were loosely aligned, with some abnormally distributing at the cerebellar surface (Fig. $3 E, F$ ). At E17, while ROR $\alpha$ positive Purkinje cells formed a normal multilayer below the EGL (Fig. 3G), GCPs appeared more dispersed in the anterior DKO cerebellar primordium when compared with control (Fig. 3G). A close examination revealed that laminin-labeled $\mathrm{BM}$ was fragmented, and scores of GCPs protruded into the adjacent subarachnoid space between the midbrain and cerebellum in the DKO embryos (Fig. $3 H$, arrows). These observations suggest that the mislocalization of Purkinje cells (supplemental Fig. S4, available at www. jneurosci.org as supplemental material, Fig. $3 F$ ) in postnatal DKO mice is likely a consequence of the anterior cerebellar malformation involving defective BM and abnormally distributed granule cells.

To probe whether loss of the BM integrity is caused by aberrant tangential migration of GCPs, we analyzed sections from earlier embryos. At E15, while the migrating GCPs had not yet arrived at the anterior cerebellum, there were already multiple small discontinuities in the BM in the DKO mice (Fig. $4 B, D^{\prime}$, arrows), suggesting that the $\mathrm{BM}$ is not disrupted by migrating GCPs. During early CNS development, radial glial processes extend from the ventricular zone to the cortical surface, where their endfeet are the preferred site of BM assembly (Halfter et al., 2000). Therefore, the failure of radial glia to maintain the BM may potentially cause its breach. Indeed, we found that the BM in the anterior cerebellum at E15 serves as the primary anchorage site for dense brain lipid-binding protein (BLBP)-positive radial glial processes (Fig. $4 C, C^{\prime}$ ). In the DKO cerebellum, radial glial processes were highly disorganized, with some of their endfeet protruding into the meninges (Fig. $4 D, D^{\prime}$, asterisk). Since the Nestin-Cre transgenic mice did not induce recombination in the ECM-secreting meningeal fibroblasts (Fig. 1E), these data provide strong evidence that $\mathrm{Abl}$ family kinases in radial glia is likely required for BM integrity. In conclusion, our time course analyses demonstrate that the abnormalities in the BM in Abl/Arg CNS-DKO embryos, likely caused by altered radial glia-BM interactions, leads to mislocalization of tangentially migrating GCPs and subsequent foliation defects in the anterior cerebellum.

\section{Abnormal Bergmann glial network and defective BM maintenance in the postnatal cerebellum}

During postnatal cerebellar development, GCPs in the EGL proliferate and give rise to differentiated granule cells that migrate
Pax6/Laminin


BLBP
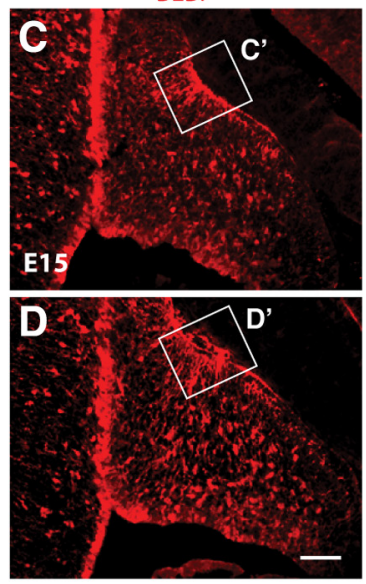

BLBP
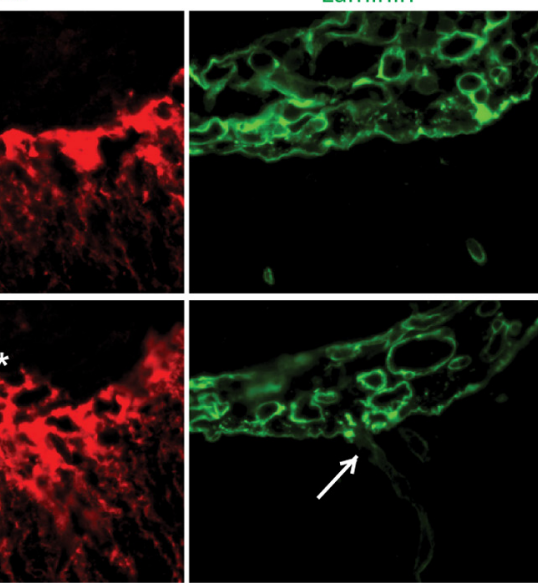
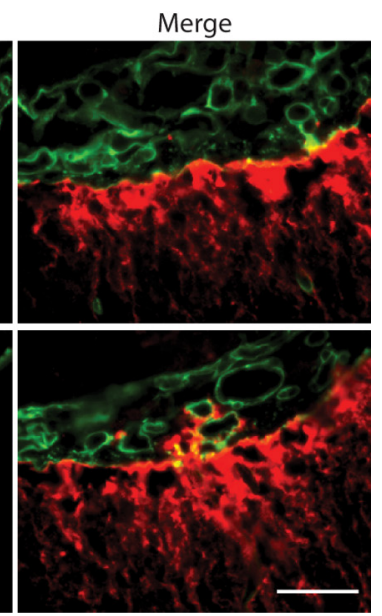

Figure 4. Disruption of the BM during embryonic development in Abl/Arg CNS-DKO mice leads to morphogenesis defects in the cerebellum. $A-D$, Abnormal radial glial endfeet and breaches of the BM precede the arrival of granule cell precursors in the indicate small ruptures in the BM. BLBP staining $(\boldsymbol{C}, \boldsymbol{D})$ of cerebellar sections showing abnormal radial glial endfeet in the DKO embryos. A higher-magnification view of BLBP and laminin costaining $\left(\boldsymbol{C}^{\prime}, \boldsymbol{D}^{\prime}\right)$ revealed protruding radial glial endfeet $\left(\boldsymbol{D}^{\prime}\right.$, asterisk) in the DK0 cerebellum. Scale bars: (in $\boldsymbol{B}, \boldsymbol{D}) \boldsymbol{A}-\boldsymbol{D}, 100 \mu \mathrm{m}$; (in $\left.\boldsymbol{D}^{\prime}\right) \boldsymbol{C}^{\prime}, \boldsymbol{D}^{\prime}, 33 \mu \mathrm{m}$.

radially along the Bergmann glial fibers and then through the PCL to form the IGL (Hatten, 1999; Sillitoe and Joyner, 2007). By $\mathrm{P} 21$, the migration of granule cells is complete and the EGL is no longer present, leaving behind the molecular layer (ML). Staining of a postmitotic neuronal marker $\mathrm{NeuN}$ showed frequent granule cell ectopias in the posterior regions of adult Abl/Arg CNS-DKO cerebella, where the basic foliation pattern was generally intact (Fig. 5A-D). Ectopic granule cells were predominately located at the cerebellar surface and along the fused fissures (Fig. $5 B$, arrow). This distribution correlated with regions in which the loss of the pial BM starting from around P8 (Fig. 5F, arrows). In control cerebellum, GFAP-labeled Bergmann glia extended processes across the ML, and their endfeet were anchored along the BM (Fig. 5G,I). In contrast, the glial fibers in the DKO mice were highly disorganized, with many random protrusions at the cerebellar surface (Fig. $5 \mathrm{H}, \mathrm{J}$ ). Since the interaction with the endfeet of Bergmann glial fibers has been suggested to be critical for maintenance of the BM in the postnatal cerebellum (Graus-Porta et al., 2001; Belvindrah et al., 2006), our results indicates that, similar to the defect in the DKO cerebellar primordium, the disruption of the $\mathrm{BM}$ in the postnatal cerebellum may likely also result from the abnormal Bergmann glial network. 

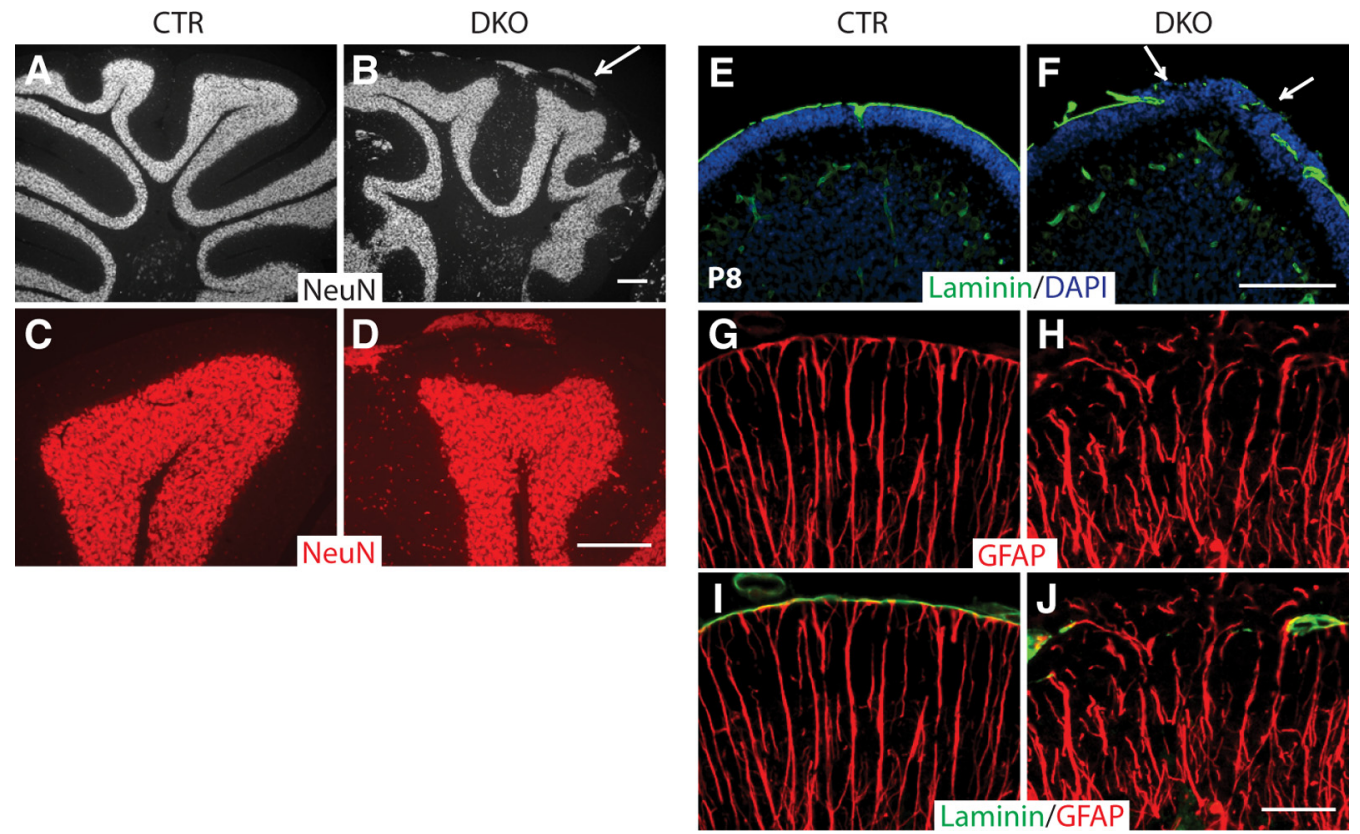

Figure 5. Abnormal Bergmann glial network and defective BM maintenance in the postnatal cerebellum of $A b l / A r g ~ C N S-D K O$ mice. $A-D$, NeuN staining of adult control (CTR) and DKO cerebellar sections showing granule cell ectopias ( $\boldsymbol{B}$, arrow) at the cerebellar surface in Ab//Arg CNS-DKO mice. $\boldsymbol{E}-\boldsymbol{J}$, Abnormal Bergmann glial network correlates with breaches of the BM ( $\boldsymbol{F}$, arrows) in the DKO cerebellum. $\boldsymbol{E}, \boldsymbol{F}$, Laminin staining of P8 (TR and DK0 cerebellar sections. $\mathbf{G}-\boldsymbol{J}$, Laminin and GFAP costaining of (TR and DKO cerebellar sections. Scale bars: (in $\boldsymbol{B}, \boldsymbol{D}, \boldsymbol{F}) \boldsymbol{A}-\boldsymbol{F}, 200 \mu \mathrm{m}$; (in $J) \mathbf{G}-\boldsymbol{J}, 33 \mu \mathrm{m}$.
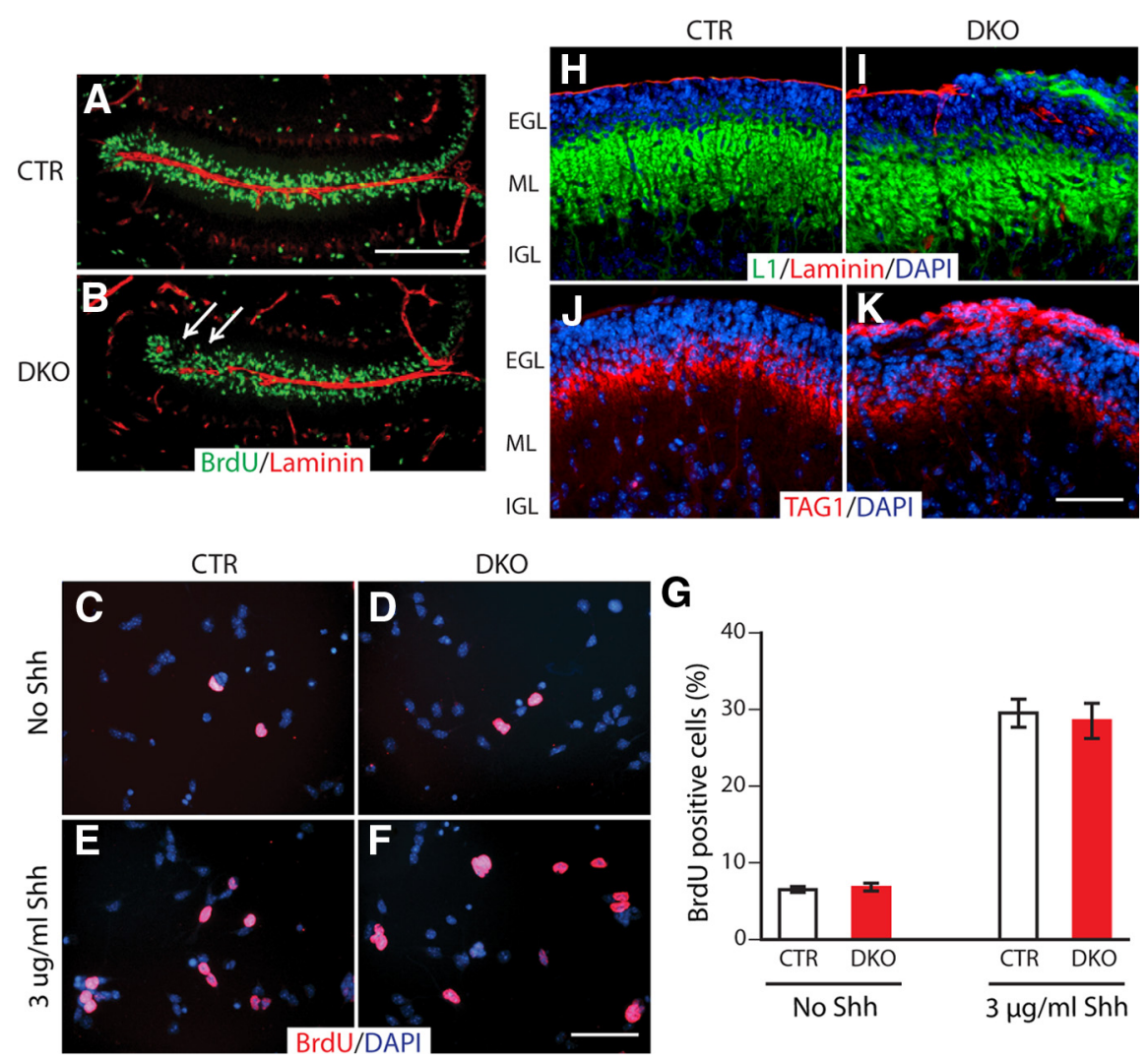

Figure 6. GCP proliferation and differentiation in Abl/Arg CNS-DKO mice. $A, B$, Decreased GCP proliferation in Abl/Arg CNS-DKO mice.P8 mice were injected with $\operatorname{BrdU}$ and killed $1 \mathrm{~h}$ later, and $\operatorname{BrdU}$ and laminin costaining $(A, B)$ of their cerebellar secondary fissure showing the reduced BrdU-positive cells ( $\boldsymbol{B}$, arrows) adjacent to the fragmented BM in the DKO mice. $\boldsymbol{C}-\boldsymbol{G}$, Normal proliferation of GCPs in the DKO cerebella-derived culture. Purified GCPs from the control (CTR) and DKO cerebella were cultured in medium with or without Shh and labeled with BrdU before fixation. The cultures were analyzed for BrdU incorporation by BrdU staining $(\boldsymbol{C}-\boldsymbol{F})$. Quantification of the percentage of BrdU-positive cells $(\boldsymbol{G})$ showing no difference; $n=3$ independent cultures for each genotype. Mean \pm SEM, $p>0.05$, Student's $t$ test. $\boldsymbol{H}-\boldsymbol{K}, \mathrm{L} 1$ and laminin costaining $(\boldsymbol{H}, \boldsymbol{I})$ and TAG1 staining $(\boldsymbol{J}, \boldsymbol{K})$ of P8 cerebellar sections showing ectopic granule cell differentiation near the broken BM in the DKO mice. Scale bars: (in $\boldsymbol{A}) \boldsymbol{A}, \boldsymbol{B}, 200 \mu \mathrm{m}$; (in $\boldsymbol{F}$ and $\boldsymbol{K}$ ) $\boldsymbol{C}-\boldsymbol{F}, \boldsymbol{H}-\boldsymbol{K}, 50 \mu \mathrm{m}$.

\section{GCP proliferation and differentiation in $\mathrm{Abl} / \mathrm{Arg} \mathrm{CNS}-\mathrm{DKO}$ mice}

With the formation and growth of the lobules, the size of the postnatal mouse cerebellum increases dramatically, which is largely caused by the proliferation of GCPs. The smaller cerebella with reduced foliation in the posterior cerebellum in the DKO mice (Fig. 2C) indicate a deficiency in GCP proliferation. To directly assess proliferative defects, we performed $1 \mathrm{~h} \mathrm{BrdU}$ pulse-labeling experiments at P8 during the peak stage of GCP proliferation (supplemental Fig. S5, available at www.jneurosci.org as supplemental material, Fig. $6 A, B)$. Because the secondary fissure is the major fissure in the posterior cerebellum, the initial formation of which is normal in the DKO mice (supplemental Fig. S5, available at www.jneurosci.org as supplemental material and Fig. $6 B$ ), we quantified the number of proliferating GCPs in it and found a significant reduction in the DKO mice $(311 \pm 17 \mathrm{BrdU}$ positive cells/mm; $n=3$ mice for each genotype) compared with controls (405 \pm 25 BrdU-positive cells/mm). Furthermore, loss of proliferating GCPs seemed to be concentrated in areas where the BM was disrupted (Fig. $6 B$, arrows). Since an intact $B M$ is important for maintaining the proliferative capacity of GCPs (Blaess et al., 2004; Belvindrah et al., 2006), these data suggest that impaired granule cell proliferation may not be a cellautonomous defect. To test this hypothe- 

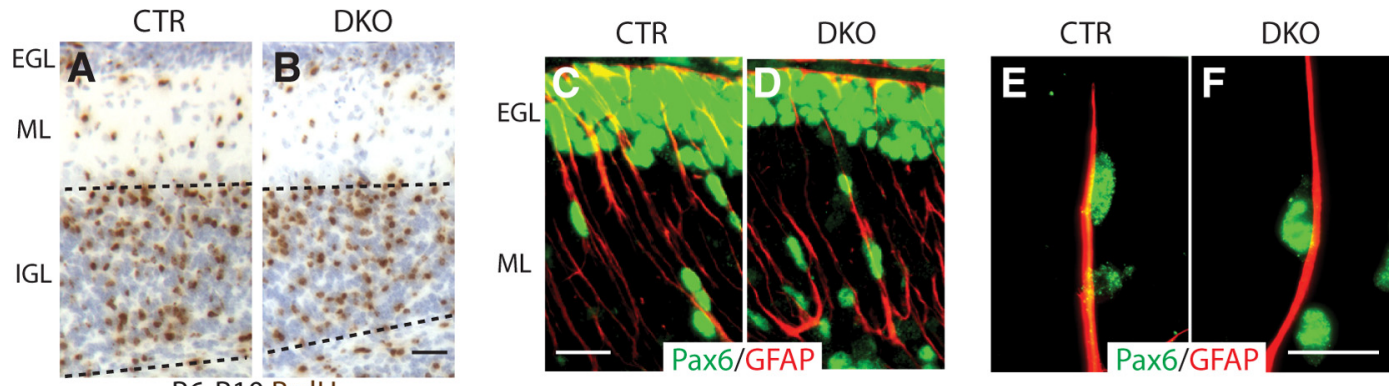

Figure 7. Granule cell migration in Abl/Arg CNS-DKO mice. $A, B$, Normal granule cell migration before the extensive loss of the BM in $A b l / A r g$ CNS-DKO mice. P6 mice were injected with BrdU and killed $4 \mathrm{~d}$ later, and their cerebellar sections were then stained with a $\operatorname{BrdU}$ antibody $(\boldsymbol{A}, \boldsymbol{B}) . \boldsymbol{C}-\boldsymbol{F}$, Normal interaction between migrating granule cell and Bergmann glial fiber in the DK0 mice. $\boldsymbol{C}, \boldsymbol{D}$, Pax6 and GFAP costaining of P10 cerebellar sections. $\boldsymbol{E}, \boldsymbol{F}$, Pax6 and GFAP costaining of cerebellar cell cultures derived from the control (CTR) and DK0 mice. Scale bars: (in $\boldsymbol{B}, \boldsymbol{C}, \boldsymbol{F}) \boldsymbol{A}-\boldsymbol{F}, 20 \mu \mathrm{m}$.

sis, we isolated granule cells from control and DKO pups and cultured them for $48 \mathrm{~h}$ in medium with or without $3 \mu \mathrm{g} / \mathrm{ml} \mathrm{Shh}$, which is a potent mitogen for GCPs and regulates the growth and elaboration of the cerebellar lobules (Corrales et al., 2006). Before fixation, cells were labeled with BrdU and the prevalence of BrdU-positive cells was determined (Fig. 6C-G). Consistent with previous studies (Wechsler-Reya and Scott, 1999), the vast majority of GCPs derived from control mice stopped proliferating in the absence of Shh, and the addition of Shh strongly promoted GCP proliferation. A similar response in proliferation of GCPs from the DKO mice was also observed (Fig. 6G), indicating that Abl kinases are not required for the proliferation of GCPs in response to Shh in vitro. This result further suggests that the decreased granule cell proliferation in the DKO mice is likely secondary to defects in the BM.

During normal differentiation, granule cells exit the cell cycle, enter the inner EGL, and spontaneously express differentiation markers such as the adhesion molecules L1 and TAG1 (Fig. $6 \mathrm{H}, \mathrm{J})$. In the DKO mice, however, with focal GCPs losing contact with the BM, they exited the cell cycle (Fig. 6B) and ectopically expressed L1 and TAG1 at the cerebellar surface (Fig. 6I, K). This might result in a depletion of the precursor pool within the EGL and likely contribute to the cerebellar hypoplasia in the DKO mice.

\section{Granule cell migration in Abl/Arg CNS-DKO mice}

The observation that granule cell ectopias formed at sites of broken BM in the postnatal DKO cerebellum (Fig. 5) raises the possibility that the phenotype is secondary to abnormalities in the $\mathrm{BM}$ and is not directly caused by intrinsic migration defects of $\mathrm{Abl} / \mathrm{Arg}$-deficient granule cells. To evaluate the rate of granule cell migration, we labeled proliferating GCPs with a single BrdU injection at $\mathrm{P} 6$ and analyzed their extent of migration at $\mathrm{P} 10$ before the extensive loss of the $\mathrm{BM}$ in the DKO mice (Fig. $7 A, B$ ). As expected, the majority of BrdU-labeled cells (90.9 $\pm 2.7 \% ; n=3$ mice for each genotype) were found in the IGL in lobule VIII in control mice. A similar percentage $(85.3 \pm 4.0 \%)$ was also observed in the same lobule in the DKO cerebella, except in few regions where the integrity of the $\mathrm{BM}$ was already destroyed and clusters of BrdU-labeled granule cells remained at the cerebellar surface (data not shown). This provides strong evidence that the intrinsic program for cerebellar granule cell migration is not perturbed in the DKO mice.

To investigate this further, we examined granule cell-glia interactions both in vivo and in vitro. The attachment of migrating granule cells to Bergmann glial fibers was readily detected in both control and DKO cerebellar sections (Fig. 7C,D). The close inter- action was also evident in cultures derived from both control and DKO mice in which many of the granule cell bodies assumed an elongated shape, indicating that they were migrating (Fig. 7 E,F). Together, these results demonstrate that Abl family kinases are not essential in either granule cell or glia for their interactions.

\section{Granule cell-specific deletion of Abl family kinases is not sufficient to induce a cerebellar lamination defect}

To further determine whether Abl family kinases in granule cells are essential for cerebellar lamination and their proliferation, we generated conditional knock-out mice in which $A b l$ was specifically deleted from granule cells using a Math1-Cre transgenic line (Matei et al., 2005). Math1-Cre was characterized by crossing with a ROSA26lacZ reporter line (Soriano, 1999). As shown by lacZ staining, Math1-Cre drives efficient recombination in all GCPs except those in the most posterior part of the cerebellum (Fig. 8A,B). Western blot analysis of cerebellar extracts from $A b l^{F / F} ; M a t h 1-C r e$ pups showed that the level of Abl protein was markedly decreased when compared with that in control mice (Fig. 8C). The residual Abl protein detected probably reflects the protein present in other Cre-negative cells such as Purkinje cells and glia in the cerebellar tissue. When $A b l^{F / F} ;$ Math1-Cre mice were crossed into the Arg knock-out background, the cerebella of the resulting mutant mice were strikingly normal, with no malformation or granule cell ectopia observed (Fig. 8D,E). Although we cannot rule out the possibility that $\mathrm{Abl}$ protein is not completely deleted in granule cells by Math1-Cre, this result provides further genetic evidence that granule cells are not the primary cause of the cerebellar lamination defects observed in $\mathrm{Abl} / \mathrm{Arg}$ CNS-DKO mice.

\section{Analysis of signaling pathways regulated by $\mathrm{Abl}$ family kinases}

In fibroblasts, integrin-mediated attachment on the ECM triggers the tyrosine phosphorylation of intracellular signaling proteins, including Abl family kinases and the adaptor protein CrkII, and leads to the rearrangement of the actin cytoskeleton (Bradley and Koleske, 2009). Interestingly, among other defects, mice lacking Crk family members in the brain also showed similar granule cell ectopias as observed in Abl/Arg CNS-DKO mice (Park and Curran, 2008). CrkII binds to the PxxP motifs of Abl family kinases through its SH3 domain (Antoku et al., 2008) and is phosphorylated by them at residue Y221 (Feller et al., 1994). When Y221 is phosphorylated, CrkII forms an intramolecular interaction with its $\mathrm{SH} 2$ domain, which blocks its activity as an adaptor protein and prevents its interaction with a key scaffold molecule, p130Cas (Kain and Klemke, 2001). While it was un- 

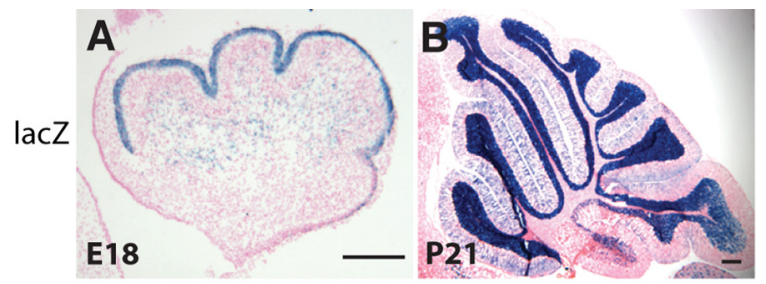

C

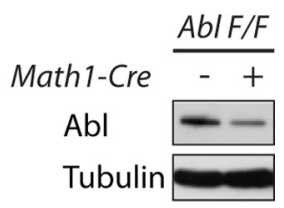

Abl F/F Arg -/-

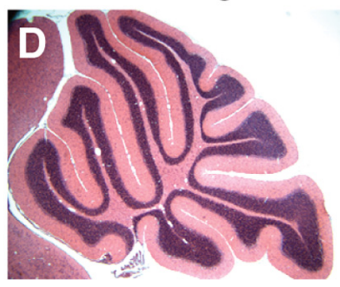

Abl F/F Arg -/-; Math1-Cre

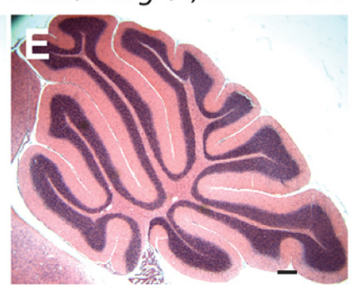

Figure 8. Granule cell-specific deletion of Abl family kinases is not sufficient to cause cerebellar lamination defect. $\boldsymbol{A}, \boldsymbol{B}$, LacZ staining of E18 ( $\boldsymbol{A})$ and P21 $(\boldsymbol{B})$ cerebellar sections from the ROSA26lacZ reporter mice showing granule cell-specific recombination mediated by Math1-Cre. C, Western blot analysis of cerebellar tissues dissected from P4 pups showing the reduced Abl expression in $A b F^{F / F} ;$ Math 1-Cre mice. D, E, H\&E staining of adult cerebellar sections showing normal lamination in $\mathrm{Abl}^{\mathrm{FFF}} ; \mathrm{Arg}^{-1-}$; Math1-Cre mice. Scale bars: (in $A, B, E) A, B, D, E, 200 \mu \mathrm{m}$

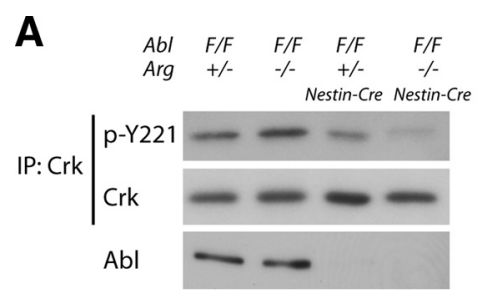

B

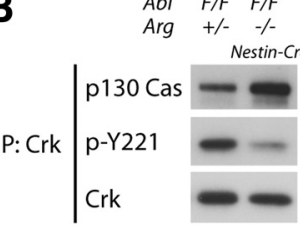

Rac1 GTP -

Rac1

C

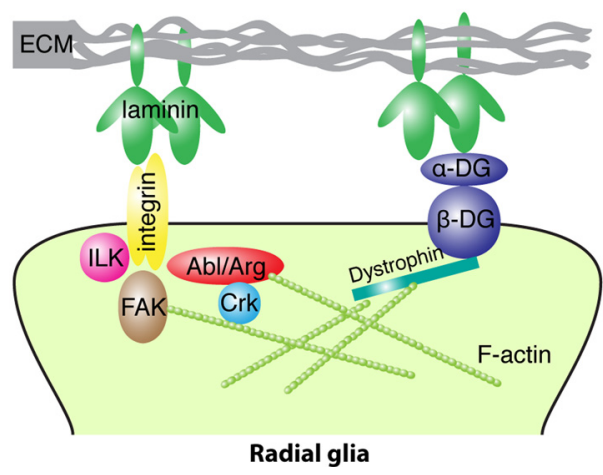

Figure 9. Crk signaling is altered in Abl/Arg-deficient brain. A, Immunoprecipitation (IP) of brain extracts from newborns with the indicated genotypes using anti-Crk antibody followed by Western blot with antibodies to phospho-Y221 (p-Y221), Crkll, and Crk. Western blot with anti-Abl antibody served as control. $\boldsymbol{B}$, Top, IP of brain extracts from newborns with indicated genotypes using anti-Crk antibody followed by Western blot with antibodies to p130Cas, p-Y221, Crkll, and Crk. Bottom, GST-Pak1-PBD pull-down of brain extracts from newborns with indicated genotypes followed by Western blot with antibody to Rac1. Western blot with antiRac1 antibody served as control. $C$, Model for the role of Abl family kinases in basement membrane maintenance. $\alpha$-DG, $\alpha$-Dystroglycan; $\beta$-DG, $\beta$-dystroglycan.

changed in $\mathrm{Arg}^{-1-}$ newborn brain extracts, phosphorylation of CrkII Y221 was significantly reduced in $\mathrm{Abl}^{\mathrm{F} / \mathrm{F}}$;Nestin-Cre extracts and almost completely abolished in $A b l / A r g$ CNS-DKO extracts (Fig. 9A). This indicates that CrkII phosphorylation at Y221 in the brain is primarily dependent on $\mathrm{Abl}$ and, to a lesser extent, on Arg. The diminished phosphorylation of CrkII Y221 also correlated with the increased association of p130Cas with Crk in the DKO extracts (Fig. 9B). Although how Abl-mediated
CrkII phosphorylation affects Racl activity is dependent on different biological contexts (Bradley and Koleske, 2009), the overall level of active Rac1 GTPase was elevated in the DKO brain extracts (Fig. 9B).

\section{Discussion}

In this study, we examined the function of Abl family kinases in brain development by generation of a new conditional $A b l$ knock-out allele. Analysis of mutant mice lacking the two kinases in the CNS reveals that Abl and Arg are both critically required for the maintenance of a normal $\mathrm{BM}$ in the cerebellum. Abl/Arg deficiency results in abnormal radial glial and Bergmann glial networks and local BM disruptions that have profound impacts on cerebellar development.

Our results demonstrate that $\mathrm{Abl} / \mathrm{Arg}$ deficiency in the brain results in local breaches in the cerebellar BM at different developmental stages, including at E15 in the anterior cerebellar primordium (Fig. 4) and after P8 in the rest of the cerebellum (Fig. 5). The loss of BM leads to severe anterior cerebellar morphogenesis defects and correlates with abnormal postnatal granule cell proliferation, migration, and differentiation. A similar phenotype in brain development was reported in mice lacking laminin receptors $\alpha$-dystroglycan and $\beta_{1}$ integrin as well as two integrin-associated signaling proteins, FAK and ILK (GrausPorta et al., 2001; Moore et al., 2002; Beggs et al., 2003; Niewmierzycka et al., 2005; Belvindrah et al., 2006; Mills et al., 2006; Satz et al., 2008). It has been proposed that the normal anchorage of radial glial endfeet and laminin binding-triggered signaling cascades in glia are important for organizing extracellular laminin and thereby maintaining the BM (Fig. 9C) (Colognato et al., 1999; Henry et al., 2001; Beggs et al., 2003). In Abl/Arg CNS-DKO mice, the fiber networks of cerebellar radial glia and Bergmann glia are both disorganized and their endfeet protruded beyond the pial surface, coinciding with regions of discontinuous BM. These observations suggest that Abl family kinases are probably required in radial glia and Bergmann glia to stabilize the BM through laminin binding-triggered signaling pathways (Fig. 9C). Consistently, time course analyses indicate that the abnormal tangential migration of GCPs into the adjacent subarachnoid space between the midbrain and cerebellum is secondary to disruptions in the BM in the DKO embryos. Moreover, we did not observe obvious defects in radial migration of postnatal granule cells before the loss of the BM or abnormal granule cell-glia interactions either in sections or in vitro culture (Fig. 7). Genetic evidence that lacking Abl kinases in cerebellar granule cells alone does not cause any lamination defect further supports a noncellautonomous role for Abl family kinases in granule cell migration and proliferation (Fig. 8). Although we still cannot exclude the possible contributions from other cerebellar neurons, such as Purkinje cells, deletion of $\mathrm{Abl} / \mathrm{Arg}$ from glia is likely required for the DKO phenotype.

Unlike $\alpha$-dystroglycan or $\beta_{1}$ integrin mutants in which the development of both cerebral cortex and cerebellum is affected, the lamination abnormalities of Abl/Arg-deficient mice are restricted to the cerebellum even though Abl kinases are ubiquitously expressed (Koleske et al., 1998) and the deletion of Abl by 
Nestin-Cre is throughout the brain (Fig. 1E). This variation could be explained by the utilization of Cre lines with different expression timing or efficiency. For example, Nestin-Cre-mediated inactivation of ILK results in only cerebellar malformations (Belvindrah et al., 2006; Mills et al., 2006), while deletion of the same gene by dorsal forebrain-specific Emx1-Cre leads to cerebral cortical defects (Niewmierzycka et al., 2005). The difference may be attributable to the slightly earlier activation of Emxl-Cre (around E9) in precursors of neurons and glia compared with that of Nestin-Cre (around E10) (Graus-Porta et al., 2001; Gorski et al., 2002). But this seems not to be the case for Abl kinases, because $\mathrm{Abl}^{\mathrm{F} / F} ; \mathrm{Arg}^{-1-} ; E m x 1-C r e$ mice still develop a normal forebrain cortex (data not shown). This argues that other kinases, such as FAK and ILK, can substitute for the function of Abl and Arg in stabilizing the BM in the brain, with the exception of the cerebellum. Interestingly, during development the cerebellum undergoes a dramatic expansion in its volume along with a unique postnatal foliation process (Sillitoe and Joyner, 2007), which might cause a prolonged and consistent mechanical pressure on its BM such that it becomes more susceptible to the loss of Abl family kinases than other brain regions.

The morphogenesis defect in the anterior cerebellum is striking and has $100 \%$ penetrance. The small disruptions of the BM in the anterior cerebellar primordium are the first detectable defects that precede the mislocalization of GCPs and failed foliation. The $\mathrm{BM}$ in the anterior cerebellum at E15 seems to be the major site for the attachment of radial glial endfeet (Fig. 4). Why it is particularly fragile during development in Abl/Arg CNS-DKO mice is still not clear. The defect is unique to Abl/Arg-deficient mice and is not observed in mutants lacking $\alpha$-dystroglycan or $\beta_{1}$ integrin in the brain (Graus-Porta et al., 2001; Moore et al., 2002). One possible explanation is that $\mathrm{Abl}$ family kinases are required for mediating signaling downstream of the engagement of both $\alpha$-dystroglycan and $\beta_{1}$ integrins in cerebellar radial glia to promote the ECM stability. Thus loss of Abl and Arg could result in a more severe phenotype in the cerebellar primordium than mutation in either $\alpha$-dystroglycan or $\beta_{1}$ integrin alone. Alternatively, Abl family kinases may be involved in signaling mediated by other unknown ECM receptors during early cerebellar development. Recently, it was reported that a mouse mutation in an orphan G protein-coupled receptor, GPR56, whose loss-offunction causes human bilateral frontoparietal polymicrogyria, results in a very similar anterior cerebellar malformation as seen in Abl/Arg CNS-DKO mice (Koirala et al., 2009). Although it has been proposed that GPR56 regulates BM integrity as a putative ECM receptor in radial glial endfeet (Li et al., 2008), GPR56 appears to specifically express in granule cells in the anterior cerebellum and controls their adhesion to the ECM (Koirala et al., 2009). The question of whether Abl family kinases are implicated in GPR56-mediated signaling merits further investigation.

How do Abl family kinases regulate BM integrity in radial glia and Bergmann glia? Since Abl family kinases are important regulators of the actin cytoskeleton downstream of $\beta_{1}$ integrins (Bradley and Koleske, 2009), deletion of Abl and Arg may prohibit the cytoskeletal rearrangement and signaling pathways that are required to transduce the bidirectional signals necessary for laminin polymerization and overall BM stability (Fig. 9C). Ablmediated Crk Y221 phosphorylation has been implicated in the regulation of multiple biological processes, including cell migration (Kain and Klemke, 2001; Noren et al., 2006), cell-cell adhesion (Zandy et al., 2007), and bacterial invasion (Burton et al., 2003). Although how Crk phosphorylation modulates the actin cytoskeleton is not fully understood (Bradley and Koleske, 2009), perturbation of the adaptor protein function could play a significant role in the DKO mutant phenotype (Fig. 9A,B). However, because loss of Crk Y221 phosphorylation is found throughout the brain in the DKO mice, but the mutant phenotype is confined to the cerebellum, this suggests that other Abl/Arg-dependent mechanisms are required in the cerebellum for BM maintenance.

The severe cerebellar displasia and hypoplasia of $\mathrm{Abl} / \mathrm{Arg}$ CNS-DKO mice resemble cerebellar defects seen in some forms of congenital muscular dystrophy, particularly Walker-Warburg Syndrome, the majority of which have an unknown genetic defect (Muntoni and Voit, 2004). This suggests that Abl family kinasemediated signaling may be perturbed in these diseases and, consequently, could play a role in their pathogenesis, although the expression levels of glycosylated $\alpha$-dystroglycan seemed to be unaffected in Abl/Arg-deficient brain (data not shown). Future studies will clarify the role of Abl family kinases in this group of diseases.

\section{References}

Agah R, Frenkel PA, French BA, Michael LH, Overbeek PA, Schneider MD (1997) Gene recombination in postmitotic cells: targeted expression of Cre recombinase provokes cardiac-restricted, site-specific rearrangement in adult ventricular muscle in vivo. J Clin Invest 100:169-179.

Antoku S, Saksela K, Rivera GM, Mayer BJ (2008) A crucial role in cell spreading for the interaction of Abl PxxP motifs with Crk and Nck adaptors. J Cell Sci 121:3071-3082.

Barresi R, Campbell KP (2006) Dystroglycan: from biosynthesis to pathogenesis of human disease. J Cell Sci 119:199-207.

Beggs HE, Schahin-Reed D, Zang K, Goebbels S, Nave KA, Gorski J, Jones KR, Sretavan D, Reichardt LF (2003) FAK deficiency in cells contributing to the basal lamina results in cortical abnormalities resembling congenital muscular dystrophies. Neuron 40:501-514.

Belvindrah R, Nalbant P, Ding S, Wu C, Bokoch GM, Müller U (2006) Integrin-linked kinase regulates Bergmann glial differentiation during cerebellar development. Mol Cell Neurosci 33:109-125.

Belvindrah R, Graus-Porta D, Goebbels S, Nave KA, Müller U (2007) Betal integrins in radial glia but not in migrating neurons are essential for the formation of cell layers in the cerebral cortex. J Neurosci 27:13854-13865.

Blaess S, Graus-Porta D, Belvindrah R, Radakovits R, Pons S, LittlewoodEvans A, Senften M, Guo H, Li Y, Miner JH, Reichardt LF, Müller U (2004) Betal-integrins are critical for cerebellar granule cell precursor proliferation. J Neurosci 24:3402-3412.

Bradley WD, Koleske AJ (2009) Regulation of cell migration and morphogenesis by Abl-family kinases: emerging mechanisms and physiological contexts. J Cell Sci 122:3441-3454.

Burton EA, Plattner R, Pendergast AM (2003) Abl tyrosine kinases are required for infection by Shigella flexneri. EMBO J 22:5471-5479.

Colognato H, Winkelmann DA, Yurchenco PD (1999) Laminin polymerization induces a receptor-cytoskeleton network. J Cell Biol 145:619-631.

Corrales JD, Blaess S, Mahoney EM, Joyner AL (2006) The level of sonic hedgehog signaling regulates the complexity of cerebellar foliation. Development 133:1811-1821.

Costell M, Gustafsson E, Aszódi A, Mörgelin M, Bloch W, Hunziker E, Addicks K, Timpl R, Fässler R (1999) Perlecan maintains the integrity of cartilage and some basement membranes. J Cell Biol 147:1109-1122.

Feller SM, Knudsen B, Hanafusa H (1994) c-Abl kinase regulates the protein binding activity of c-Crk. EMBO J 13:2341-2351.

Georges-Labouesse E, Mark M, Messaddeq N, Gansmüller A (1998) Essential role of alpha 6 integrins in cortical and retinal lamination. Curr Biol 8:983-986.

Gorski JA, Talley T, Qiu M, Puelles L, Rubenstein JL, Jones KR (2002) Cortical excitatory neurons and glia, but not GABAergic neurons, are produced in the Emx1-expressing lineage. J Neurosci 22:6309-6314.

Graus-Porta D, Blaess S, Senften M, Littlewood-Evans A, Damsky C, Huang Z, Orban P, Klein R, Schittny JC, Müller U (2001) Betal-class integrins regulate the development of laminae and folia in the cerebral and cerebellar cortex. Neuron 31:367-379.

Gu H, Zou YR, Rajewsky K (1993) Independent control of immunoglobulin switch recombination at individual switch regions evidenced through Cre-loxP-mediated gene targeting. Cell 73:1155-1164. 
Halfter W, Dong S, Schurer B, Osanger A, Schneider W, Ruegg M, Cole GJ (2000) Composition, synthesis, and assembly of the embryonic chick retinal basal lamina. Dev Biol 220:111-128.

Halfter W, Dong S, Yip YP, Willem M, Mayer U (2002) A critical function of the pial basement membrane in cortical histogenesis. J Neurosci 22:6029-6040.

Hatten ME (1999) Central nervous system neuronal migration. Annu Rev Neurosci 22:511-539.

Hatten ME, Liem RK, Mason CA (1986) Weaver mouse cerebellar granule neurons fail to migrate on wild-type astroglial processes in vitro. J Neurosci 6:2676-2683

Henry MD, Satz JS, Brakebusch C, Costell M, Gustafsson E, Fässler R, Campbell KP (2001) Distinct roles for dystroglycan, betal integrin and perlecan in cell surface laminin organization. J Cell Sci 114:1137-1144.

Kain KH, Klemke RL (2001) Inhibition of cell migration by Abl family tyrosine kinases through uncoupling of Crk-CAS complexes. J Biol Chem 276:16185-16192.

Koirala S, Jin Z, Piao X, Corfas G (2009) GPR56-regulated granule cell adhesion is essential for rostral cerebellar development. J Neurosci 29:7439-7449.

Koleske AJ, Gifford AM, Scott ML, Nee M, Bronson RT, Miczek KA, Baltimore D (1998) Essential roles for the Abl and Arg tyrosine kinases in neurulation. Neuron 21:1259-1272.

Lee HY, Greene LA, Mason CA, Manzini MC (2009) Isolation and culture of post-natal mouse cerebellar granule neuron progenitor cells and neurons. J Vis Exp pii:990.

Li S, Jin Z, Koirala S, Bu L, Xu L, Hynes RO, Walsh CA, Corfas G, Piao X (2008) GPR56 regulates pial basement membrane integrity and cortical lamination. J Neurosci 28:5817-5826.

Matei V, Pauley S, Kaing S, Rowitch D, Beisel KW, Morris K, Feng F, Jones K, Lee J, Fritzsch B (2005) Smaller inner ear sensory epithelia in Neurog 1 null mice are related to earlier hair cell cycle exit. Dev Dyn 234:633-650.

Mills J, Niewmierzycka A, Oloumi A, Rico B, St-Arnaud R, Mackenzie IR, Mawji NM, Wilson J, Reichardt LF, Dedhar S (2006) Critical role of integrin-linked kinase in granule cell precursor proliferation and cerebellar development. J Neurosci 26:830-840.

Miner JH, Cunningham J, Sanes JR (1998) Roles for laminin in embryogenesis: exencephaly, syndactyly, and placentopathy in mice lacking the laminin alpha5 chain. J Cell Biol 143:1713-1723.

Moore SA, Saito F, Chen J, Michele DE, Henry MD, Messing A, Cohn RD, Ross-Barta SE, Westra S, Williamson RA, Hoshi T, Campbell KP (2002) Deletion of brain dystroglycan recapitulates aspects of congenital muscular dystrophy. Nature 418:422-425.

Muntoni F, Voit T (2004) The congenital muscular dystrophies in 2004: a century of exciting progress. Neuromuscul Disord 14:635-649.

Niewmierzycka A, Mills J, St-Arnaud R, Dedhar S, Reichardt LF (2005) Integrin-linked kinase deletion from mouse cortex results in cortical lam- ination defects resembling cobblestone lissencephaly. J Neurosci 25: 7022-7031.

Noren NK, Foos G, Hauser CA, Pasquale EB (2006) The EphB4 receptor suppresses breast cancer cell tumorigenicity through an Abl-Crk pathway. Nat Cell Biol 8:815-825.

Olson EC, Walsh CA (2002) Smooth, rough and upside-down neocortical development. Curr Opin Genet Dev 12:320-327.

Park TJ, Curran T (2008) Crk and Crk-like play essential overlapping roles downstream of disabled-1 in the Reelin pathway. J Neurosci 28:13551-13562.

Pendergast AM (2002) The Abl family kinases: mechanisms of regulation and signaling. Adv Cancer Res 85:51-100.

Qiu Z, Cang Y, Goff SP (2010) c-Abl tyrosine kinase regulates cardiac growth and development. Proc Natl Acad Sci U S A 107:1136-1141.

Satz JS, Barresi R, Durbeej M, Willer T, Turner A, Moore SA, Campbell KP (2008) Brain and eye malformations resembling Walker-Warburg syndrome are recapitulated in mice by dystroglycan deletion in the epiblast. J Neurosci 28:10567-10575.

Schwartzberg PL, Stall AM, Hardin JD, Bowdish KS, Humaran T, Boast S, Harbison ML, Robertson EJ, Goff SP (1991) Mice homozygous for the ablm1 mutation show poor viability and depletion of selected B and T cell populations. Cell 65:1165-1175.

Sievers J, Pehlemann FW, Gude S, Berry M (1994) Meningeal cells organize the superficial glia limitans of the cerebellum and produce components of both the interstitial matrix and the basement membrane. J Neurocytol 23:135-149.

Sillitoe RV, Joyner AL (2007) Morphology, molecular codes, and circuitry produce the three-dimensional complexity of the cerebellum. Annu Rev Cell Dev Biol 23:549-577.

Soriano P (1999) Generalized lacZ expression with the ROSA26 Cre reporter strain. Nat Genet 21:70-71.

Stanley JL, Lincoln RJ, Brown TA, McDonald LM, Dawson GR, Reynolds DS (2005) The mouse beam walking assay offers improved sensitivity over the mouse rotarod in determining motor coordination deficits induced by benzodiazepines. J Psychopharmacol 19:221-227.

Tronche F, Kellendonk C, Kretz O, Gass P, Anlag K, Orban PC, Bock R, Klein R, Schütz G (1999) Disruption of the glucocorticoid receptor gene in the nervous system results in reduced anxiety. Nat Genet 23:99-103.

Tybulewicz VL, Crawford CE, Jackson PK, Bronson RT, Mulligan RC (1991) Neonatal lethality and lymphopenia in mice with a homozygous disruption of the c-abl proto-oncogene. Cell 65:1153-1163.

Wechsler-Reya RJ, Scott MP (1999) Control of neuronal precursor proliferation in the cerebellum by Sonic Hedgehog. Neuron 22:103-114.

Woodring PJ, Hunter T, Wang JY (2003) Regulation of F-actin-dependent processes by the Abl family of tyrosine kinases. J Cell Sci 116:2613-2626.

Zandy NL, Playford M, Pendergast AM (2007) Abl tyrosine kinases regulate cell-cell adhesion through Rho GTPases. Proc Natl Acad Sci U S A 104: 17686-17691. 